\title{
APOPTOTIC AND VASCULAR CHANGES IN TRICHINELLA SPIRALIS IN FECTED MICE AFTER PARENTERAL ARTEMETHER TREATMENT
}

\author{
By \\ SHEREEN MAHMOUD IBRAHIM ${ }^{1}$, MOHAMED HASSAN SARHAN ${ }^{1 *}$, \\ TAHANI ISMAIL FARAG ${ }^{1}$ AND ASMAA HUSSEIN MOHAMED ${ }^{2}$ \\ Departments of Medical Parasitology ${ }^{1}$ and Pathology ${ }^{2}$, Faculty of Medicine, \\ Zagazig University, Zagazig 44519, Egypt \\ ( ${ }^{\star}$ Correspondence: drsarhan@gmail.com)

\section{Abstract}

Trichinosis is a parasitic disease, caused by a nematode worm of the genus Trichinella. Infection is caused by ingestion of undercooked contaminated meat with infective parasitic larvae. The study assessed the muscle apoptotic and vascular changes in T. spiralis infected mice after intra-muscular artemether injection. This study included 80 clean laboratory-bred Swiss albino mice orally infected with 200 T. spiralis larvae/mouse. Four groups of mice (20 mice each), GI: non-infected (control normal); GII: infected untreated (control infected); GIII: infected then treated with artemether injection $1.25 \mathrm{mg} / \mathrm{kg}$ 45days post-infection (dpi) and GIV: infected then treated with artemether injection $25 \mathrm{mg} / \mathrm{kg}$ $45 \mathrm{dpi}$. On the $60^{\text {th }} \mathrm{dpi}$, mice were sacrificed. All groups were evaluated parasitologically by assessing the number of intestinal worms and muscular encysted larvae, histopathological assessment of intestinal and muscle changes and immune-histochemical assessment of BAX marker for apoptotic changes and CD34 marker for vascular changes.

Keywords: Apoptotic changes, Artemether, BAX, CD34, Trichinella spiralis

\section{Introduction}

Trichinosis is one of the zoonotic parasitosis caused by a nematode of genus Trichinella, worldwide distribution (11 million) and many cases were found in Egypt (Gottstein et al, 2009). Trichinosis is caused by ingestion of undercooked pig meat containing the infective larvae in muscles (Dupouy-Camet, 2000), zoonotic trichinosis outbreaks occurred (Turk et al, 2006).

Diarrhea is the commonest symptom in trichinosis, while fever, periorbital edema, and myositis occur during the infection course. Patients may manifest severe illness due to myocarditis, pneumonia or encephalitis depending on number of larvae ingested (Grove, 2000). T. spiralis starts in host skeletal muscle then modifies and utilizes the host system to build its capsule in these muscles which is composed of a collagenous wall that provides some protection to the parasite and a cellular component. This cellular component is formed of some infected myocytes with the function of nourishment of the parasite as well as its protection from the host immune response, and both layers are of the host origin (Bruschi and Chiumiento, 2011).
Muscle cell necrosis occur early after muscle injury followed by accumulation of inflammatory cells within damaged tissues. Then, the parasite initiates angiogenesis and attracts a highly permeable set of blood vessels to the surface of its collagenous capsule (Despommier, 1998). T. spiralis accomplishes nutrient acquisition \& waste disposal to maintain a long-term host-parasite relationship by attracting a set of permeable blood vessels to the surface of collagenous capsule (Ock et al, 2013).

Necrosis of muscle cells occurs with severe damage that prevents cells repairing. This necrotic area is removed by scavenger cells through phagocytosis, but muscle cells may undergo apoptosis or recover from damage by repairing itself with little damage (Wu et al, 2008). Acceleration of apoptosis transformed the skeletal muscle cell into a nurse cell with comfortable lodging for the parasite (Boonmars et al, 2004). Matsuo et al. (2000) found that T. spiralis-in muscle cells showed differentfeatures of basophilic cytoplasm characteristic to apoptosis. Many genes and signaling pathways mobilized in nurse cell formation like the mitochondrial pathway mediated, and death receptor path- 
way me-diated apoptosis signaling, or genes rela-ted to cell differentiation, proliferation, cell cycle control, and apoptosis-related involved in capsule formation of trichinosis (Wu et al, 2008).

$\mathrm{Bcl}-2$ associated protein $\mathrm{X}(\mathrm{BAX})$ is a proapoptotic member of the $\mathrm{Bc} 1-2$ protein family; previous immunocytochemical studies showed that the apoptotic and the proapoptotic genes such as p53 and BAX genes respectively were expressed in the nucleoplasm of basophilic cell in the cyst and Trichinella larvae, suggesting the involvement of these genes in nurse cell formation (Boonmars et al, 2004). BAX induced apoptosis by forming membrane pore in mitochondria for cytochro-me c to be released upon apoptotic signaling (Parone et al, 2002). Different cell surface markers purified adult stem cell populations from skeletal muscle, including CD34 \& CD45 (Arinobu et al, 2005). CD34 is a surface glycol phospho-protein expressed in early hematolymphoid stem cell stage to define a subpopulation of pri-mitive hematopoietic progenitor cells (HPCs) with a high potential to differentiate along myoendothelial lineages in vitro (Pesce et al, 2003). HPCs start to differentiate into small vessel (Yin et al, 1997), but they still expressed CD34 (Fina et $a l$, 1990), contributing to regenerate muscle fibers (Torrente et al, 2004) and neovascularization (Kawamoto et al, 2006).

Human circulating CD34+HPCs underwent myogenic differentiation when exposed to certain cytokines in culture (Pesce $e t$ $a l, 2003)$. Also, they were able to imp- rove neovascularization in ischemic tissu- es (Ribatti, 2007).

Hollemann et al. (2008) on skeletal muscle of patients with inflammatory myositis (IM), and numerous interstitial mononuclear cells, found when diffusely interspe-rsed in areas of inflammation and tissue injury, there were expressed CD34 antigens. The CD34coexpression in skeletal muscle with IM caused recruitment of circulating HPCs into the myogenic pathway in man due to inflammatory damage.

Artemisinin ${ }^{\circledR}$ drug reduced inflammation and angiogenesis in infected $T$. spiralis muscles, which proved effective in trichinosis treatment (Abou Rayia et al, 2017).

This study aimed to evaluate the expression of pro-apoptotic gene BAX and vascular marker CD34 immunohistochemica-lly on muscles of mice experimentally infected with $T$. spiralis and treated with two doses of artemether to assess muscle apoptotic and vascular changes in them.

\section{Materials and methods}

Animals, parasite, and infection: A total of 80 clean laboratory-bred Swiss Albino mice of 5 weeks old, weighing 20-25gm each, were used. They were obtained from the Animal House, Faculty of Medicine, Zagazig University. T. spiralis isolate was obtained from infected Albino mice, at experimental house, Department of Medical Parasitology, Faculty of Medicine, Ta-nta University, and maintained in Zagazig Medical Parasitology Laboratory, by consecutive passages. Mice were left for 4 days to adapt before being experimented with, then infected orally with 200 T. spiralis larvae/ mouse (Dunn and Wright, 1985).

Experimental design: Eighty mice were divided into 4 groups of 20 mice each. GI: non-infected control group. GII: Infected untreated (control infected), GIII: Infected and treated with artemether injection 1.25 $\mathrm{mg} / \mathrm{kg}$ 45days post-infection (dpi), and GIV: Infected and treated with artemether injection $25 \mathrm{mg} / \mathrm{kg} 45 \mathrm{dpi}$. On the $60^{\text {th }}$ dpi, mice were sacrificed.

Diaphragm, tongue, triceps, biceps brachialis, and quadriceps femoralis muscles were dissected out. Muscle samples were histopathological and immunohistochemical studies. Second muscle part was digested in artificial digestion for larval count by Trichinoscopy.

Artemether intramuscular injection was given in a single low dose $(12.5 \mathrm{mg} / \mathrm{kg})$ at $45^{\text {th }}$ dpi (Akomolafe et al, 2011), and a sin- 
gle high dose $(25 \mathrm{mg} / \mathrm{kg})$ at $45^{\text {th }}$ dpi (Clemmer et al, 2011).

$T$. spiralis isolation for counting: The intestine was cut into pieces of nearly $1 \mathrm{~cm}$ each and incubated at $37^{\circ} \mathrm{C}$ in $10 \mathrm{ml}$ of Hanks balanced salt solution (HBSS) for $2 \mathrm{hr}$ to allow worms migration from tissue. The intestine was washed several times with HBSS. This fluid was collected and centrifuged at $1500 \mathrm{rpm}$ for $10 \mathrm{~min}$. Sediment reconstituted in 3-5 drops of HBSS were examined at $10 \times$ to count adult worms (Issa $e t$ al, 1998).

T. spiralis larval in muscles (Trichinoscopy): Mice were dissected, eviscerated, and cut into pieces; digested in 1\% HCL, $1 \%$ (1/10.000) pepsin \& 200ml distilled water and then incubated at $37^{\circ} \mathrm{C}$ for $2 \mathrm{hr}$ with continuous stirring. Digested muscles were sieved (50 mesh/inch) to remove coarse particles. The recovered larvae were sieved (200mesh/inch) sieved, twice washed with distilled water and lastly suspended in $200 \mathrm{ml}$ of tap water in a flask. Larvae sediment was counted by Mc-Ma- ster counting chamber (Denham, 1965).

Histopathological analysis: Intestinal and muscular samples of all groups were fixed in $10 \%$ formalin for $48 \mathrm{hr}$, washed in water for $12 \mathrm{hr}$, dehydrated in ethanol, cleared in xylene and embedded in paraffin blocks, and then sectioned at $5 \mu \mathrm{m}$ thickness by microtome and stained with hematoxylin and eosin (Drury et al, 1967). The intestinal specimens were evaluated for intensity of inflammatory cellular infil-trate within villi and submucosa, the shape and size of villi and presence of goblet cells microscopy (x10 \& x100). For skeletal muscle specimens number of larvae per low power field was counted, and intensity of the inflammatory reaction around capsule was evaluated.

Immunohistochemical study: Sections were prepared from muscle blocks. Slides were deparaffinized with xylene $\left(37^{\circ} \mathrm{C}\right)$, dehydrated in ethanol series and rehydrat- ed in water. Methanol and peroxide were used in one block of endogenous pero-xidase and distilled water and peroxide in second block. Incubation was done with the two primary antibodies chosen: Rabbit polyclonal antibodies to BAX (BAX, San-ta Cruz Biotechnology Inc., CA, USA) and CD34 (polyclonal, Thermo Scienti-fic ${ }^{\circledR}, \quad 1: 100$, CA). The secondary antibody (Advance TM HRP Dako), associated with dextran polymer, was left with mate-rial for $30 \mathrm{~min}$ at room temperature. 3-3'-diaminobenzidine (DAB) and substrate (DAB liquid DakoCytomation ${ }^{\circledR}$ chromo-genic substrate system Dako ${ }^{\circledR}$ ) were added and counterstaining was done with hema-toxylin followed by dehydration with abs-olute ethanol, clearing with xylene, moun-ted in Canada balsam. Negative controls were made by substitution of primary anti-bodies. Positive and negative controls were included in all runs. Slides were pho-tographed. Evaluation of immunohisto-chemical BAX \& CD34 expression was done semiquantitively by immunostain-ing intensity as strong, moderate and mild expression.

Animal ethics: All mice were reared and sacrificed according to the international guidelines approved by The Institutional Animal Care and Use Committee, Zagazig University (IACUC-ZU).

Statistical analysis: Expression of quantitative values of parameters was done, as mean \pm standard deviation (SD). Data were analyzed by ANOVA test for significance differences between groups using SPSS (version 14.0). Difference was considered significant if $\mathrm{P}<0.05$, highly significant if $\mathrm{P}$ $<0.01$ and not significant if $\mathrm{P}>0.05$.

Drug efficacy or reduction percentage $(\mathrm{R} \%)$ was calculated using equation $(\mathrm{R} \%)=$ $100 \times$ (mean number in controls - mean number in treated mice) / mean number in controls.

\section{Results}

Parasitological evaluation was given in tables (1\& 2) and figures (1, 2, $3 \& 4)$. 
Table 1: T. spiralis worm count in intestine of infected control, ART LD treated \& ART HD treated groups.

\begin{tabular}{|c|c|c|c|}
\hline Variants & GI (control infected) & GII (ART LD) & GIII (ART HD) \\
\hline Mean \pm SD & $77.3 \pm 8.3$ & $22.55 \pm 2.9$ & $9.05 \pm 0.9$ \\
\hline $\mathrm{R} \%$ & -- & $70.8 \%$ & $88.2 \%$ \\
\hline P value & \multicolumn{3}{|c|}{} \\
\hline
\end{tabular}

Number of worms in small intestine decreased significantly after artemether low dose (22.55 \pm 2.9$)$ and high dose (9.05 \pm 0.9$)$ compared with control infected untreated $(77.3 \pm 8.3)$ group $(\mathrm{p}<0.001)$ and reduction $(70.8 \% \& 88.2 \%)$ respectively. A high significant difference was between infected groups treated with artemether.

Table 2: Mean T. spiralis larval count in muscle of infected control (GI), ART LD (GII) \& ART HD (GIII).

\begin{tabular}{|c|c|c|c|}
\hline Variants & GI (control infected) & GII (ART LD) & GIII (ART HD) \\
\hline Mean \pm SD & $48631 \pm 4172.8$ & $13767.5 \pm 1873.7$ & $9275 \pm 2314.0$ \\
\hline $\mathrm{R} \%$ & -- & $71.6 \%$ & $80.9 \%$ \\
\hline P value & \multicolumn{3}{|c|}{$<0.001$} \\
\hline
\end{tabular}

Number of larvae in muscle of ART LD was reduced $(13767.5 \pm 1873.7)$ and with ART HD was $(9275 \pm 2314.0)$ and reduction (71.6\% \& 80.9\%) respectively compared to control infected untreated $(48631 \pm 4172.8)$ group. There was a high-ly significant difference between infected artemether treated groups $(\mathrm{p}<0.001)$.

Histopthological evaluation was given (figures 1\&2): Intestinal larvae in infected control group showed dense cellular inflammatory infiltrates by lymphocytes, plasma cells, eosinophils with few neutrophils accompanied with flattening of intestinal villi with marked hyperplasia of crypts \& goblet cell hyperplasia (Fig. 1a),

Increased dilated blood vessels were in intestinal core (Fig. 1b). The artemethertreated groups; ART LD group showed decrease in number of goblet cells with moderate cellular inflammatory infiltrates and recovery some of villi (Fig 1c), ART HD group showed complete recovery of villi with mild inflammatory infiltrates (Fig. 1d).

Muscle larvae in infected control group showed dense inflammatory infiltrates around capsule of encysted larvae with some of degeneration in muscle fibers and increased numbers of larvae deposition. Each one was surrounded by a collagen-ous capsule and heavy inflammatory cell-ular infiltrations (Fig. 2a, b \& e).

Histopathological changes in muscles of both drug-treated groups showed marked significant reduction in number of larvae and intensity of inflammatory infiltrate compared to infected control group. This reduction was more in ART HD treated group with destruction of surrounding capsule (Fig. 2d \&g) compared to ART LD treated group (Fig. 2c\&f).

Immunohistochemical evaluation: Stro-ng cytoplasmic BAX staining was in cellular infiltrates around capsule of encysted larva of infected group (Fig 3a). ART LD treated group showed moderate cytoplasmic expression of BAX at poles of encys-ted larva with incomplete capsule (Fig. 3b). ART HD treated group showed mild cytoplasmic BAX expression around degenerated larva (Fig. 3c).

CD 34 expression in innfected group showed strong cytoplasmic membrane expression of CD34 staining around encysted larva, cellular infiltrates between muscle bundles probably differentiating endothelial cells (myoendothelial cells) and proliferating capillary network (Fig. 4a). ART LD treated group showed larva with moderate expression of CD34 in interstitial spaces of muscle bundles (Fig. 4b), while ART HD treated group showed mild CD34 expression between muscle bundles with regular capillary architecture and mononuclear cells infiltrates around degenerated larva with destructed capsule (Fig. 4c).

\section{Discussion}

The main drugs for trichinosis are Albendazole $^{\circledR}$ \& Mebendazole ${ }^{\circledR}$ (Gottstein et al, 
2009). But, these drugs gave unsatisfa-fctory effect on encapsulated larval stages (Caner et al, 2008), with poor water solubility that limited absorption and bioavailability (Derda et al, 2003; Garcia et al, 2003). Some of these drugs were contraindicated in pregnancy and pediatrics less than three years old (Yadav and Temjenmongla, 2012), while others are carcinogenic (Shalaby et al, 2010). A safe and effective anthelminthic agent especially against encapsulated muscle larvae was a must (Yadav and Temjenmongla, 2012).

Artemisinin reduced both the inflammatory and angiogenesis process in T. spira- lis infected muscles (Abou Rayia et al, 2017). The destructive actions of artemisinin and its derivatives against some helminthic parasites were reported. Xiao and Catto (1989) and Elshafey et al. (2018) re-ported tegumental damage of adult schist- osomes after in vitro incubation with arte- mether. The in vitro destruction of artemether against toxocaraisis canis was report-ed (Shalaby et al, 2009) who found that it caused sloughing, swelling and damage to the cuticle doses of the worm.

In the present study, high significant reduction was in adult worm of groups treated with low and high of intramuscular artemether $(70.8 \%$ \& $88.2 \%)$ respectively compared to infected control group. These results agreed with Abou Rayia et al. (2017) who reported the therapeutic effect of artemisinin in mice experimentally infected with T. spiralis with reduction of adult worm count $(75 \%)$ as compared to infected control group.

The present study revealed a high significant decrease in muscle larval count in mice groups treated with low and high dose artemether $(71.6 \%$ \& $80.9 \%)$ respectively as compared to infected control group. These findings agreed with Abou Rayia et al. (2017) who reported that artemisin given to $T$. spiralis experimentally infected mice showed $72 \%$ reduction of muscle larval count as compared to infected control. Caner et al. (2008) found effectiveness of 2 extracts from Artemisia; A. vulgaris and A. obsinthium against tri-chinosis in rats gave $65.8 \%$ \& $51.9 \%$ respectively reduction in larval count.

Generally, Xiao and Catto (1989), Wang et al. (2014) and Elshafey et al. (2018) reported that artemisinin and its derivatives excerted a high effect against adult $S$. japonicum and $S$. mansoni and their larval stages with reduction of egg counts and adult worm with a consequent improvement in liver pathology of infected mice.

The activity of artemisinin against parasites was mediated mainly through the release of free radicals (Derda et al, 2016). Kołodziej-Sobocińska (2006) found that the liberated free radicals was highly toxic to parasites and have a role in the activation of host immune response during intestinal and muscle phases of $T$. spiralis infection. Also, several studies reported that artemisinin induced suppression of Th- $1 \&$ Th-17 immune responses and pro-moted increase in Th-2 responses and serum IL4 \& IL10 levels that mediated adult $T$. spiralis expulsion and regulated cellular responses and reduced immunopatholog-ical damage respectively (Finkelman et al, 2004; Hou et al, 2011; 2012).

In the present work, the decreased count of adults in ART LD treated mice was accompanied by decrease in number of goblet cells with moderate inflammatory infiltrate in intestinal core and recovery of some villi, in ART HD treated group. The intestine showed complete villi recovery with mild inflammatory infiltrate in intestinal core. The decrease of larval count in muscle of ART LD treated mice was accompanied with decreased inflammatory reaction while ART HD treated group showed mild inflammatory infiltrates with degeneration of larva and without capsule. Bruschi et al. (2003) reported the host tissue damage in muscle phase of $T$. spiralis infection caused by invading parasite and inflammatory cells that produced high lev-els of reactive oxy- 
gen intermediates and stress markers as cyclooxygenase and tra-nsferase.

BAX is a pro-apoptotic member of Bc1-2 protein family and accelerates apoptosis induced by different stimuli (Oltvai et al, 1993). During apoptosis, cytosolic and monomeric BAX translocated to the mitochondrial membranes (Goping et al, 1998; Hsu et al, 1997; Wolter et al, 1997) and induced mitochondrial membrane potential and cytochrome c release and caspase activation (Narita et al, 1998).

In the present study, artemether on BAX marker expression in muscles show-ed that expression of BAX increased in T. spiralisinfected muscles during encapsulation phase. Sandri and Carraro (1999) reported that apoptosis-related genes were involved in formation of $T$. spiralis caps- ule. Apoptotic genes were involved in cell suicide with a role in different physiological processes, and deregulation of apoptosis process implicated in disease pathology. Boonmars et al. (2004) found strong positive staining for mitochondrial apop-tosis related genes (BAX; apoptotic protease activating factor 1, Apaf-1; Caspase 9 \& serine/threonine protein kinase, PKB), with elevation in infected muscles with $T$. spiralis in encapsulation phase.

In the present study the ART LD treated mice showed encysted larva with moderate cytoplasmic expression of BAX at capsule poles, and ART HD treated mice showed mild cytoplasmic BAX exp-ression around degenerated larva.

In order to stay in nurse cell, the larva promoted angiogenesis process and attracted set of highly permeable blood vessels to the surface of the collagenous capsule called vascular rete to maintain good nutrition (Baruch and Despommier, 1991).

In the present study the expression of CD34 marker in $T$. spiralis infected muscles was elevated during the encapsulation phase mostly due to inflammatory myositis caused by infection and significantly decreased with artemether treatment. This agreed with Hol- lemann et al. (2008) who suggested that circulating HPCs including CD34 expressing cells colonize skeletal muscle in inflammatory conditions and provide evidence for myoendothelial differentiation of some of these cells. They stated that a significant increase in the numbers of CD34+ cells was found in polymyositis and inclusion body myositis compared with control normals, indicating endothelial or myogenic commitment of some HPCs in skeletal muscle.

\section{Conclusions}

The outcome results showed that artemether proved useful and safe as an alternative treatment of trichinosis spiralis. Art- emether caused a significant reduction in adult and larval counts. The drug reduced the expression of proapoptotic BAX gene and angiogenic marker CD34 in muscles, and thus could reduce $T$. spiralis-associa-ted myositis.

Conflict of interest: Authors neither have any interest nor received financial support.

\section{References}

Abou Rayia, DM, Saad, AE, Ashour, DS, Oreiby, RM, 2017: Implication of artemisinin nematocidal activity on experimental trichinellosis: In vitro and in vivo studies. Parasitol. Int. 66:56-63.

Akomolafe, RO, Adeoshun, IO, Fakunle, J B, Iwalewa, EO, Ayoka, AO, et al, 2011: Ef-fects of artemether on the plasma and urine concentrations of some electrolytes in rats. Afric.J. Biotechnol. 10:4226-33.

Arinobu, Y, Iwasaki, H, Gurish, MF, Mizuno, S, Shigematsu, H, et al, 2005: Developmental checkpoints of the basophil/mast cell lineages in adult murine hematopoiesis. Proc. Natl. Acad. Sci. USA 102:18105-10.

Baruch, AM, Despommier, DD, 1991: Blo-od vessels in Trichinella spiralis infections: a study using vascular casts. J. Parasitol. 77:99-103.

Boonmars, T, Wu, Z, Nagano, I, Takaha-shi, Y, 2004: Expression of apoptosis-related factors in muscles infected with Trichinella spiralis. Parasitology 128:323-32.

Bruschi, F, Chiumiento, L, 2011: Trichinella inflammatory myopathy: Host or parasite strategy? Parasit. Vect. 4:42-6.

Bruschi, F, Saviozzi, M, Piaggi, S, Malvaldi, G, Casini, A, 2003: Up-regulation of the $31 \mathrm{kDa}$ 
dehydroascorbate reductase in the mo-dified skeletal muscle cell (nurse cell) during Trichinella spp. infection. Int. J. Parasitol. 33: 103542.

Caner, A, Döşkaya, M, Değirmenci, A, Can, H, Baykan, S, et al, 2008: Comparison of the effects of Artemisia vulgaris and Artemisia absinthium growing in western Anatolia against trichinellosis (Trichinella spiralis) in rats. Exp. Parasitol. 119:173-9.

Clemmer, L, Martins, YC, Zanini, GM, Frangos, JA, Carvalho, LJ, 2011: Artemether and artesunate show the highest efficacies in rescuing mice with late-stage cerebral malaria and rapidly decrease leukocyte accumulation in the brain. Antimicrob. Agents Chemother. 55:1383-90.

Denham, DA, 1965: Studies with methyrid- ine and Trichinella spiralis. I. Effect upon the intestinal phase in mice. Exp. Parasitol. 17:10-14.

Derda, M, Boczoń, K, Wandurska-Nowak, E, Wojt, W, 2003: Changes in the activity of glutathione-S-transferase in muscles and sera from mice infected with Trichinella spiralis after treatment with albendazole and levamisole. Parasitol. Res. 89:509-12.

Derda, M, Hadaś, E, Cholewiński, M, Skrzypczak, L, Grzondziel, A, et al, 2016: Artemisia апnиa $L$. as a plant with potential use in the treatment of acanthamoebiasis. Parasitol. Res. 115:1635-9.

Despommier, DD, 1998: How does Trichinella spiralis make itself at home? Parasitol. Today 14:318-23.

Drury, R, Wallington, E, Cancerson, R, 1967: Carleton's Histological Technique ( $4^{\text {th }}$ Edition). Oxford University Press, Oxford, UK.

Dunn, IJ, Wright, KA, 1985: Cell injury caused by Trichinella spiralis in the mucosal epithelium of B10A mice. J. Parasitol. 71: 757-66.

Dupouy-Camet, J, 2000: Trichinellosis: A worldwide zoonosis. Vet. Parasitol. 93:191-200.

Elshafey, MA, Etewa, SE, Sarhan, MH, Arafa, SZA, Abo el-maaty, DA, et al, 2018: Ultrastructural and muscular modifications of adult Schistosoma mansoni worms induced by artemether (ART) in vitro. J. Egypt. Soc. Parasitol. 48:101-107.

Fina, L, Molgaard, HV, Robertson, D, Bradley, NJ, Monaghan, P, et al, 1990: Expression of the CD34 gene in vascular endothelial cells. Blood 75:2417-26.
Finkelman, FD, Shea-Donohue, T, Morris, SC, Gildea, L, Strait, R, et al, 2004: Interleukin-4- and interleukin-13-mediated host protection against intestinal nematode parasites. Immunol. Rev. 201:139-55.

García, JJ, Bolás, F, Torrado, JJ, 2003: Bioavailability and efficacy characteristics of two different oral liquid formulations of albendazole. Int. J. Pharm. 250:351-8.

Goping, IS, Gross, A, Lavoie, JN, Nguyen, M, Jemmerson, R, et al, 1998: Regulated targeting of BAX to mitochondria. J. Cell. Biol. 143:207-15.

Gottstein, B，Pozio， E，Nöckler，K，2009: Epidemiology, diagnosis, treatment, and control of trichinellosis. Clin. Microbiol. Rev. 22: 127-45.

Grove, DI, 2000: Tissue nematodes including Trichinosis, Dracunculiasis and Filariasis. In: Mandell, GL, Bennett, JE, Dolin, R (eds) Principles and Practice of Infectious Diseases, $5^{\text {th }}$ ed. Churchill Livingstone, Philadelphia.

Hollemann, D, Budka, H, Löscher, WN, Yanagida, G, Fischer, MB, et al, 2008: Endothelial and myogenic differentiation of he-matopoietic progenitor cells in inflammatory myopathies. J. Neuropathol. Exp. Neurol. 67: 711-9.

Hou, LF, He, SJ, Li, X, Wan, CP, Yang, Y, et al, 2012: SM934 treated lupus-prone NZB $\times$ NZW F1 mice by enhancing macrophage interleukin-10 production and suppressing pathogenic T cell development. PLoS One 7: e32424.

Hou, LF, He, SJ, Li, X, Yang, Y, He, PL, et al, 2011: Oral administration of artemisinin analog SM934 ameliorates lupus syndromes in MRL/lpr mice by inhibiting Th1 and Th17 cell responses. Arthritis Rheum. 63:2445-55.

Hsu, YT, Youle, RJ, 1997: Nonionic detergents induce dimerization among members of the Bcl-2 family. J. Biol. Chem. 272:13829-34.

Issa, RM, El-Arousy, MH, Abd EI-Aal, AA, 1998: Albendazole: a study of its effect on experimental Trichinella spiralis infection in ra-ts. Egypt. J. Med. Sci. 19:281-90.

Kawamoto, A, Iwasaki, H, Kusano, K, Murayama, T, Oyamada, A et al, 2006: CD34positive cells exhibit increased potency and safety for therapeutic neovascularization after myocardial infarction compared with total mononuclear cells. Circulation 114:2163-9.

Kołodziej-Sobocińska, M, 2006: Influence of free radicals on Trichinella spiralis infection in mice. Wiad. Parazytol. 52:239-41. 
Matsuo, A, Wu, Z, Nagano, I, Takahashi, Y, 2000: Five types of nuclei present in the capsule of Trichinella spiralis. Parasitology 121:203-10. Narita, M, Shimizu, S, Ito, T, Chittenden, T, Lutz, RJ, et al, 1998: Bax interacts with the permeability transition pore to induce permeability transition and cytochrome c release in isolated mitochondria. Proc. Natl. Acad.

Sci. USA 95:14681-6.

Ock, MS, Cha, H-J, Choi, YH, 2013: Verifiable hypotheses for thymosin $\beta 4$-dependent and independent angiogenic induction of Tri-chinella spiralis-triggered nurse cell forma-tion. Int. J. Mol. Sci. 14:23492-8.

Oltvai, ZN, Milliman, CL, Korsmeyer, SJ, 1993: Bcl-2 heterodimerizes in vivo with a conserved homolog, Bax, that accelerates programmed cell death. Cell 74:609-19.

Parone, PA, James, D, Martinou, JC, 2002: Mitochondria: regulating the inevitable. Biochimie. 84:105-11.

Pesce, M, Orlandi, A, Iachininoto, MG, Straino, S, Torella, AR, et al, 2003: Myoendothelial differentiation of human umbilical cord blood-derived stem cells in ischemic limb tissues. Circ. Res. 93:e51-62.

Ribatti, D, 2007: The discovery of endothelial progenitor cells. An historical review. Le-uk. Res. 31:439-44.

Sandri, M, Carraro, U, 1999: Apoptosis of skeletal muscles during development and disease. Int. J. Biochem. Cell. Biol. 31:1373-90.

Shalaby, HA, Abdel-Shafy, S, Abdel-Rahman, KA, Derbala, AA, 2009: Comparative in vitro effect of artemether and albendazole on adult Toxocara canis. Parasitol. Res. 105: 96776.

Shalaby, MA, Moghazy, FM, Shalaby, HA, Nasr, SM, 2010: Effect of methanolic extract of Balanites aegyptiaca fruits on enteral and paren- teral stages of Trichinella spiralis in rats. Parasitol. Res. 107:17-25.

Torrente, Y, Belicchi, M, Sampaolesi, M, Pisati, F, Meregalli, M et al, 2004: Human circulating AC133(+) stem cells restore dys

trophin expression and ameliorate function in dystrophic skeletal muscle. J. Clin. Invest. 114:182-95.

Turk, M, Kaptan, F, Turker, N, Korkmaz, M, El, S, Ozkaya, D, et al, 2006: Clinical and laboratory aspects of a trichinellosis outbreak in Izmir, Turkey. Parasite 13:65-70.

Wang, W, Li, TY, Ji, Y, Qu, GL, Qian, YL, et al, 2014: Efficacy of artemether and arte-sunate in mice infected with praziquantel nonsusceptible isolate of Schistosoma japonicum. Parasitol. Res. 113:925-31.

Wolter, KG, Hsu, YT, Smith, CL, Nechushtan, A, Xi, XG, et al, 1997: Movement of Bax from the cytosol to mitochondria during apoptosis. J. Cell. Biol. 139:1281-92.

Wu, Z, Nagano, I, Takahashi, Y, 2008: Candidate genes responsible for common and different pathology of infected muscle tissues between Trichinella spiralis and T. pseudospira-lis infection. Parasitol. Int. 57:368-78.

Xiao, SH, Catto, BA, 1989: In vitro and in vivo studies of the effect of artemether on Schistosoma mansoni. Antimicrob. Agents Chemother. 33:1557-62.

Yadav, AK, Temjenmongla, 2006: Anthelmintic activity of Gynura angulosa DC against Trichinella spiralis infections in mice. PhOL. 2:299-306.

Yadav, AK, Temjenmongla, 2012: Efficacy of Lasia spinosa leaf extract in treating mice infected with Trichinella spiralis. Parasitol. Res. 110:493-8. Yin, AH, Miraglia, S, Zanjani, ED, AlmeidaPorada, G, Ogawa, M, et al, 1997: AC 133, a novel marker for human hematopoietic stem and progenitor cells. Blood 90:5002-12.

\section{Legend of Figures}

Fig. 1: Histopathological small intestine sections of infected mice $(\mathrm{H} \& \mathrm{E} \times 400)$. (a) Infected untreated group (GI) showing dense inflammatory infiltrates in mucosa and submucosa and flattening of intestinal villi with crypts hyperplasia. (b) Low dose artemether treated group (GII) showing intestinal core with heavy cellular inflammatory infiltrates and increasing apoptotic nuclei and increased blood vessels. (c) Low dose artemether treated group (GII) showing moderate inflammatory infiltrates in intestinal core with decreased number of goblet cells and recovery some of villi. (d) High dose artemether treated group (GIII) showing complete recovery of villi with mild inflammatory infiltrates in intestinal core and decreased blood vessels numbers.

Fig. 2: Histopathological muscle sections of infected mice. (a) Infected group (GI) showing dense inflammatory infiltrates around the capsule of encysted larva with some degeneration of muscle fibers. (b) infected group (GI) showing increased dilated blood vessels around encysted larva with necrosis of muscle fibers. (c) Low dose artemether treated group (GII) showing decline of the numbers of encysted larva with incomplete capsules around homogenized acidophilic substance from degenerated larva (arrow) and decreasing inflammatory infiltrates around them. (d) High dose treated group (GIII) showing mild cellular inflammatory infiltrates around degenerated homogenized larva with complete destruction of the capsule (arrow) and decreased of tissue reactions.

Fig. 2': Histopathological muscle sections of infected mice. (e) Infected group (GI) showing dense inflammatory infiltrates mainly lymphocyts around encysted larva and between musle fibers. (f) Low dose artemether treated group (GII) showing incomplete destruction of 
capsule around degenerated larva with mild inflammatory reaction. (g) High dose treated group (GIII) showing homogenized acidophilic degenerated larva with complete destruction of capsule.

Fig. 3: Expression of BAX in infected muscle of mice (Immunoperoxidase $\times 400$ ). (a) Infected group (GI) showing strong cytoplasmic expression of BAX staining in cellular infiltrates around encysted larva. (b) Low dose artemether group (GII) showing encysted larva with moderate cytoplasmic expression of BAX in cellular infiltrates at poles of its capsule. (c) High dose group (GIII) showing mild cytoplasmic BAX expression around degenerated larva with destruction of capsule.

Fig. 4: Expression of CD34 in infected muscle. (a) Infected group (GI) showing strong CD34 expression in cellular infiltrates around encysted larva \& interstitial spaces of muscle bundles with proliferating capillaries. (b) Low dose artemether group (GII) showing moderate CD34 staining in cellular infiltrates of interstitial spaces between muscle bundles with irregular capillary architecture and around degenerated larva. (c) High dose group (GIII) showing mild expression of CD34 between muscle bundles with regular capillary network and cellular infiltrates around homogenized degenerated larva with complete absent of capsule.
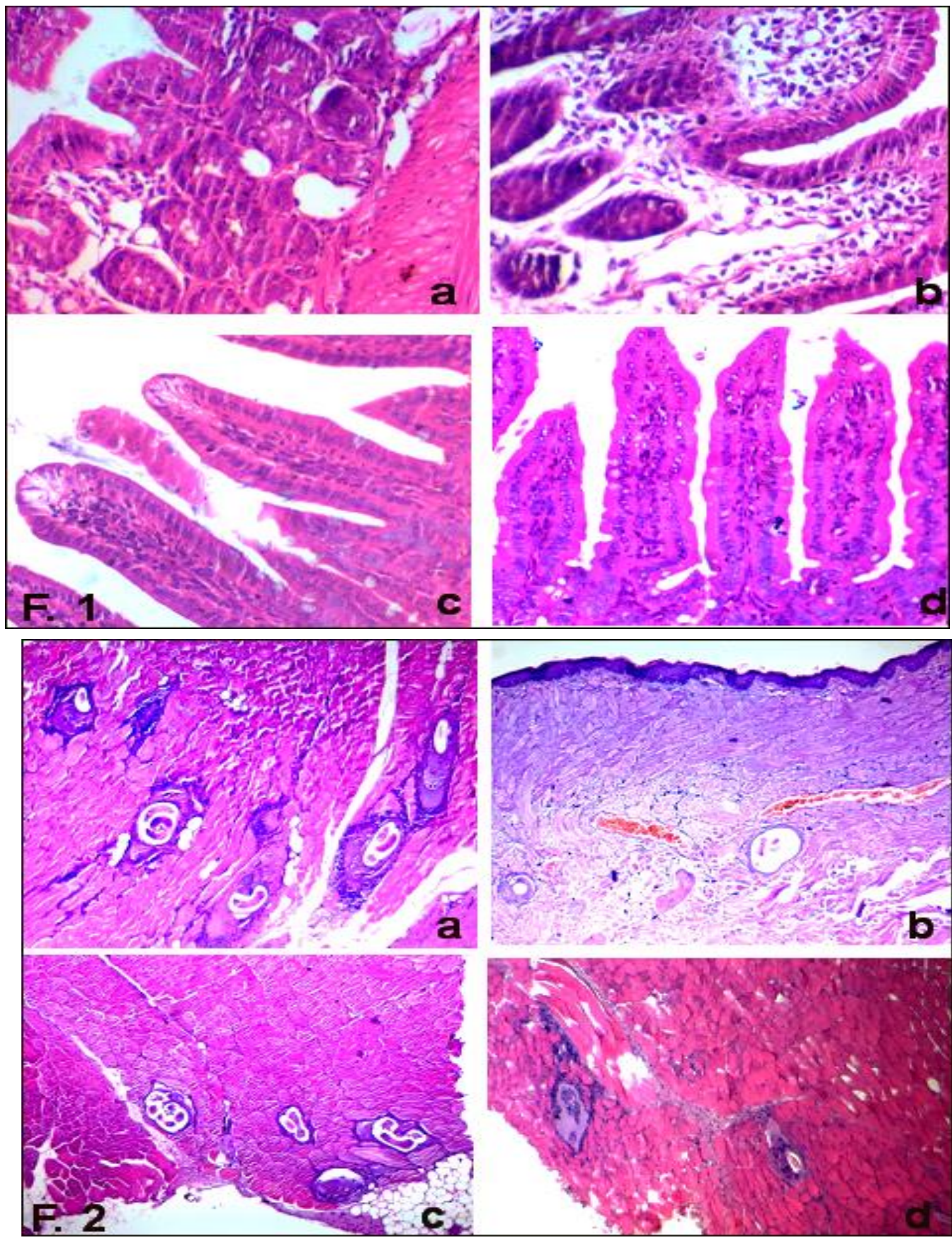

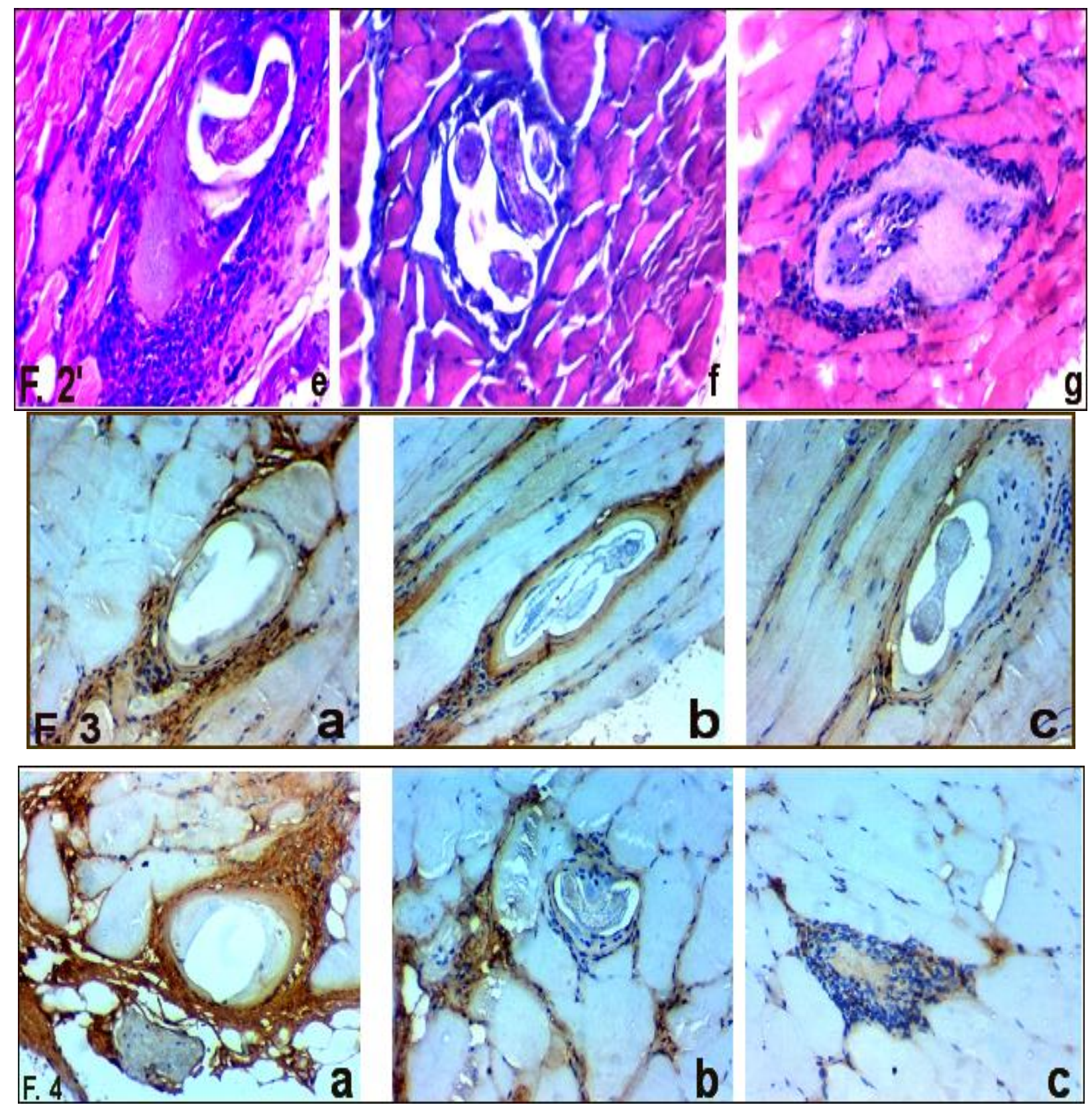